\title{
Properties of Electrosynthesized Cobalt Doped Zinc Selenide Thin Films Deposited at Varying Time
}

\author{
Ezenwaka, L. N. ${ }^{1}$, Okoli, N. L. ${ }^{1,2^{*}(\mathbb{0}}$, Okereke, N. A. ${ }^{1}$, Ezenwa, I. A. ${ }^{1}$, Nwori, N. A. ${ }^{1]}$ \\ ${ }^{1}$ Department of Industrial Physics, Chukwuemeka Odumegwu Ojukwu University, Uli, Anambra State, Nigeria \\ ${ }^{2}$ Department of Physics, Legacy University Okija, Anambra State, Nigeria \\ Email: okolinonsolivinus@gmail.com; okoli.nl@legacyuniversity.edu.ng
}

Received: 15 July 2021; Revised: 17 August 2021; Accepted: 02 September 2021

\begin{abstract}
Time optimized cobalt-doped zinc selenide thin films have been successfully electrodeposited on fluorinedoped tin oxide substrates. The films were deposited at the varying time of $1 \mathrm{~min}, 3 \mathrm{mins}$, and $5 \mathrm{mins}$ respectively. Film thickness, optical, structural, electrical, and morphological properties of the deposited thin films were evaluated. Film thickness estimated using the gravimetric method increased from $294.35 \mathrm{~nm}$ to $399.62 \mathrm{~nm}$ as deposition time increased. Optical properties showed that the absorbance of the films ranged from $13.58 \%$ to $83.15 \%$ and was found to increase as deposition time increased. Transmittance ranged from $24.40 \%$ to $73.15 \%$ and was found to decrease as deposition time increased. The reflectance of the films was found to be low while the energy band gap ranged between $2.10 \mathrm{eV}$ and 2.85 $\mathrm{eV}$. Structural properties confirmed the deposition of $\mathrm{ZnSe}$ thin film with crystallite size values that fall between 14.68 $\mathrm{nm}$ and $18.60 \mathrm{~nm}$. Dislocation density is ranged from $4.66 \times 10^{15}$ lines $/ \mathrm{m}^{2}$ to $2.97 \times 10^{15}$ lines $/ \mathrm{m}^{2}$ while microstrain ranged between $8.53 \times 10^{-3}$ and $5.83 \times 10^{-3}$. Crystallite sizes of the films were found to increase as deposition time increased while dislocation density and microstrain were found to decrease as deposition time increased. Electrical properties showed that the deposited films are semiconducting films with electrical resistivity values of $1.54 \times 10^{5} \Omega$ $\mathrm{cm}-1.83 \times 10^{4} \Omega \mathrm{cm}$ and electrical conductivity values of $6.30 \times 10^{-6} \mathrm{~S} / \mathrm{cm}-5.47 \times 10^{-5} \mathrm{~S} / \mathrm{cm}$. The micrograph of the films showed that the films were made up of nanoparticles and nanofibres of different dimensions. Energy-Dispersive X-Ray Spectroscopy (EDS) spectra of the films confirmed the presence of cobalt, zinc, and selenium.
\end{abstract}

Keywords: electrosynthesis, zinc selenide, cobalt dopant, deposition time, optoelectrical properties

\section{Introduction}

Over years, zinc selenide ( $\mathrm{ZnSe}$ ) thin films have been researched due to the promising properties that make them suitable materials for use in optoelectronics such as blue-green lasers, light-emitting diode, optically controlled switches, photoconductors [1-2]. Its unique electrical and optical properties have positioned it as a potential material for thin-film devices such as photoluminescent and electroluminescent devices and as an n-type window (buffer) layer in chalcogenide-based thin-film heterojunction solar cells [3]. Zinc selenide as a semiconducting material has a bulk energy bandgap of $\sim 2.70 \mathrm{eV}[4]$. These properties could be modified by varying the growth parameters such as dopant concentration, $\mathrm{pH}$, deposition duration, deposition potential, and others. Owing to these properties, different methods have been adopted to prepare the $\mathrm{ZnSe}$ crystals as well as thin films. These methods include; chemical bath deposition

Copyright (C2021 Okoli, N. L., et al.

DOI: https://doi.org/10.37256/nat.3120221040

This is an open-access article distributed under a CC BY license

(Creative Commons Attribution 4.0 International License)

https://creativecommons.org/licenses/by/4.0/ 
[5-9], chemical vapor deposition [10-11], thermal evaporation [12-13], electrodeposition [14-17] and pulsed laser deposition [18-19]. Cobalt is a potential dopant material in the $\mathrm{ZnSe}$ system due to its relative ionic radii $\left(\mathrm{Zn}^{2+} \rightarrow 0.74\right.$ $\AA$ and $\mathrm{Co}^{2+} \rightarrow 0.75 \AA$ ). Co-doped zinc selenide ( $\mathrm{ZnSe}: \mathrm{Co}$ ) thin films have been investigated by [20-22] for various applications. Their results showed enhancement in the properties of $\mathrm{ZnSe}$ thin films when cobalt ions were introduced into the structure of $\mathrm{ZnSe}$ thin films.

Electrodeposition is a good technique for the fabrication of uniform and adhesive thin films due to its costeffectiveness, easy scale-up, good control of material structure, and corresponding substrate flexibility [23]. This process involves the driving of cations to the cathode by an electric force. At the cathode, the cations are reduced to metals, alloy, or react with each other to form a compound. Setup for electrodeposition can be either two-electrode or three-electrode configuration. A two-electrode configuration system consists of an anode and a cathode while the threeelectrode configuration system consists of the working electrode, counter electrode, and reference electrode. In this work, the three-electrode setup was used in the synthesis of the cobalt-doped zinc selenide.

To the best of our knowledge, the effect of deposition time on the properties of electrodeposited cobalt doped zinc selenide has not been reported elsewhere. This formed the motivation for this work. This work studied the effect of deposition time on the optical, structural, electrical, and morphological properties of electrodeposited cobalt doped zinc selenide thin films deposited at room temperature. The deposited thin films of ZnSe were subjected to optical, structural, electrical, and morphological analyses.

\section{Materials and methods}

\subsection{Experimental procedures}

Three electrodes setup was used to deposit cobalt doped zinc selenide thin films on fluorine-doped tin oxide (FTO) substrate. FTO was used as the working electrode, the platinum rod was used as counter electrode while $\mathrm{Ag} / \mathrm{AgCl} / \mathrm{Cl}^{-}$ electrode was used as the reference electrode. Dazheng digital DC-power supply unit (model: PS-1502A) was used as a voltage supply source. Two digital multimeters (DT9291A and Mastech: MY60) were used for measuring voltage and current respectively. Figure 1 showed the electrodeposition setup for deposition cobalt doped zinc selenide.

For the growth of cobalt-doped zinc selenide thin film on FTO substrate, the aqueous electrolytic bath composed of $15 \mathrm{ml}$ of $0.240 \mathrm{M}$ zinc acetate, $15 \mathrm{ml}$ of $0.010 \mathrm{M}$ of cobalt nitrate, $15 \mathrm{ml}$ of $0.20 \mathrm{M}$ selenium dioxide was prepared and magnetically stirred for 5 minutes. $5 \mathrm{ml}$ of $0.05 \mathrm{M} \mathrm{NaSO}_{4}$ which served as a supporting electrolyte and $5 \mathrm{ml}$ of 0.1 $\mathrm{M} \mathrm{H}_{2} \mathrm{SO}_{4}$ that served as a $\mathrm{pH}$ adjuster were added to the initial mixture under continuous stirring. The final solution was stirred for 5 minutes followed by immersion of the three electrodes into the bath containing the electrolytic solution and 4 volts were allowed to pass through the setup for 1 minute $(1 \mathrm{~min})$. Two other samples were deposited at times 3 minutes ( 3 mins) and 5 minutes (5 mins) respectively. Table 1 shows the constituents of the electrolytic baths.

Table 1. Bath parameter of time optimized $Z n_{1-x} C o_{x} S e$ thin film

\begin{tabular}{cccccccccccc}
\hline \multicolumn{2}{c}{$\mathrm{Zn}$ ion Precursor } & \multicolumn{2}{c}{ Co ion Precursor } & \multicolumn{2}{c}{ Se ion Precursor } & \multicolumn{2}{c}{$\mathrm{Na}_{2} \mathrm{SO}_{4}$} & & $\mathrm{H}_{2} \mathrm{SO}_{4}$ & Voltage & Time \\
\hline $\begin{array}{c}\text { Con. } \\
(\mathrm{mole})\end{array}$ & $\begin{array}{c}\text { Vol. } \\
(\mathrm{ml})\end{array}$ & $\begin{array}{c}\text { Con. } \\
(\mathrm{mole})\end{array}$ & $\begin{array}{c}\text { Vol. } \\
(\mathrm{ml})\end{array}$ & $\begin{array}{c}\text { Con. } \\
(\mathrm{mole})\end{array}$ & $\begin{array}{c}\text { Vol. } \\
(\mathrm{ml})\end{array}$ & $\begin{array}{c}\text { Con. } \\
(\mathrm{mole})\end{array}$ & $\begin{array}{c}\text { Vol. } \\
(\mathrm{ml})\end{array}$ & $\begin{array}{c}\text { Con. } \\
(\mathrm{mole})\end{array}$ & $\begin{array}{c}\text { Vol. } \\
(\mathrm{ml})\end{array}$ & $\begin{array}{c}\text { (volts) } \\
(\mathrm{mins})\end{array}$ \\
0.240 & 15.00 & 0.010 & 15.00 & 0.20 & 15.00 & 0.05 & 5.00 & 0.10 & 5.00 & 4.00 & 1.0 \\
0.240 & 15.00 & 0.010 & 15.00 & 0.20 & 15.00 & 0.05 & 5.00 & 0.10 & 5.00 & 4.00 & 3.0 \\
0.240 & 15.00 & 0.010 & 15.00 & 0.20 & 15.00 & 0.05 & 5.00 & 0.10 & 5.00 & 4.00 & 5.0 \\
\hline
\end{tabular}




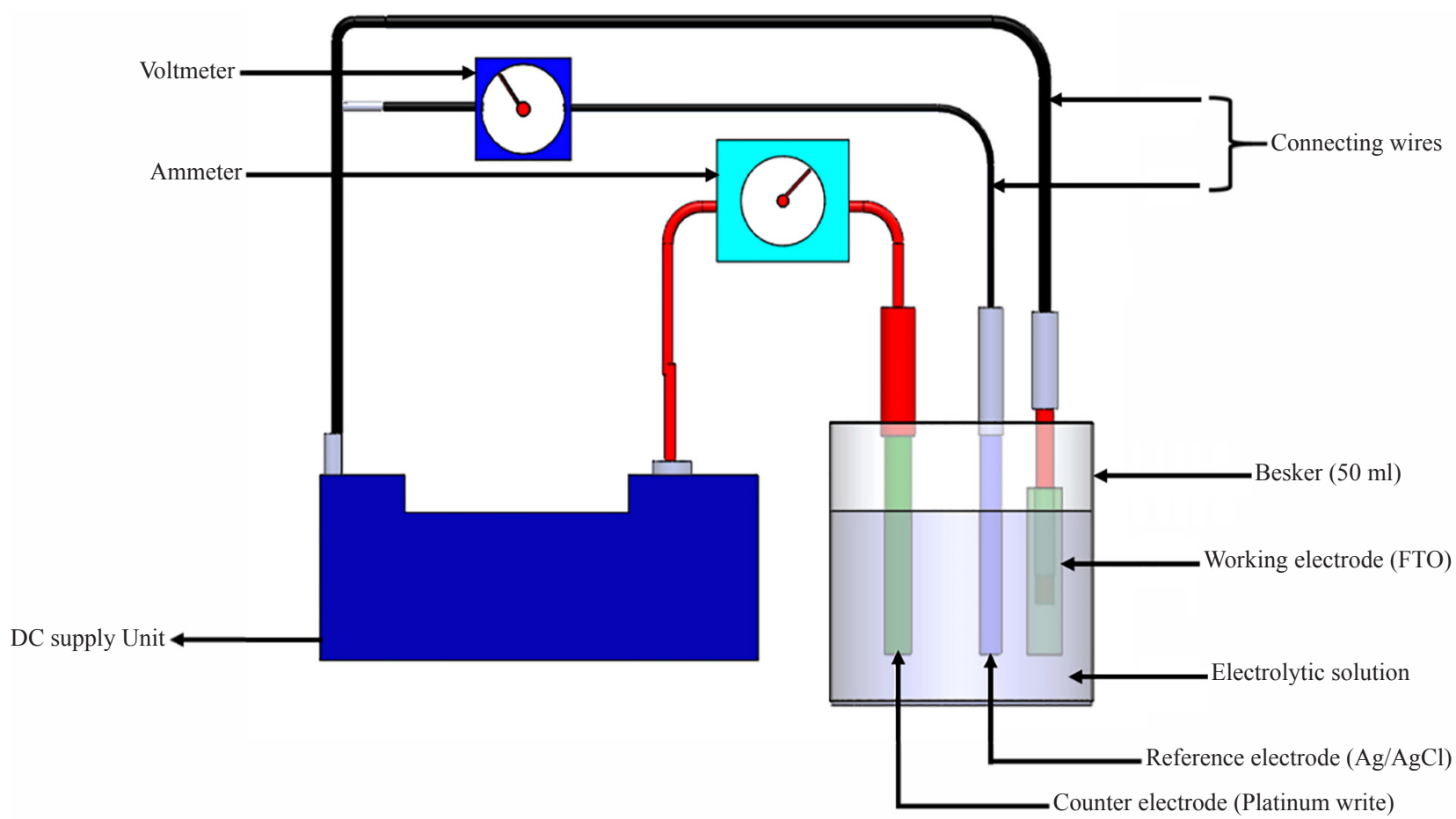

Figure 1. Schematic diagram of the electrodeposition experimental set-up

\subsection{Characterization techniques}

Film thickness was carried out using the gravimetric method. Structural analyses of the thin films were studied using the X-ray diffraction (XRD) machine (Buker D8 high-resolution diffractometer) at Material Research Department, iThemba Labs, Johannesburg, South Africa. Optical and electrical properties were evaluated using UVVIS spectrophotometer (model: 756S UV-VIS) and four-point probe (Keithley 2400-LV source meter) at Nano Research Laboratory, Department of Physics and Astronomy, University of Nigeria Nsukka, Enugu State, Nigeria. Morphological analysis of the film was done using the scanning electron microscope (MIRA TESCAN SEM) located at the Electron Microscope Unit, University of Cape Town, South Africa.

\section{Results and discussion}

\subsection{Thickness measurement}

Thicknesses (t) of the deposited thin films were evaluated using the gravimetric method given in equation (1) by [24-25].

$$
d=\frac{\Delta m}{\rho A},
$$

where $\Delta m$ is the change in mass of the thin film. A is the surface area of the deposited film and $\rho$ is the bulk density of the material. The masses of the deposited films were obtained by finding the difference in mass between the mass of the glass substrate and the film after deposition and the mass of the glass substrate before deposition. Figure 2 showed the graph of thickness plotted against deposition time. The result showed that the thickness of the films increased as deposition time increases. The optimal thickness of $399.62 \mathrm{~nm}$ was obtained at a deposition time of 5 mins while the least thickness of $294.35 \mathrm{~nm}$ was obtained at $1 \mathrm{~min}$ of deposition time. This trend of increase in thickness as deposition 
time increases is similar to those obtained by [26-29].

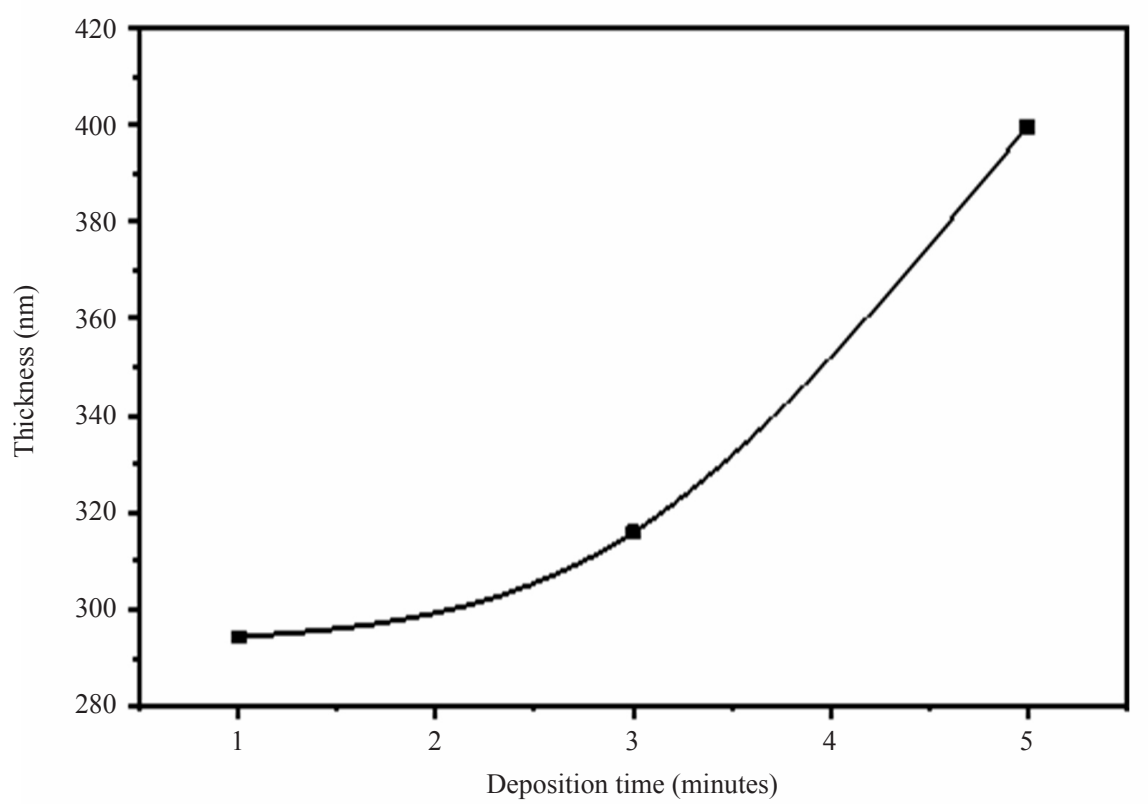

Figure 2. Variation of thin film thickness with deposition time

\subsection{Structural analysis}

Figure 3 shows the x-ray diffraction patterns of cobalt-doped zinc selenide thin films deposited under different deposition times of $1 \mathrm{~min}, 3$ mins, and 5 mins. The x-ray diffractograms correspond to diffraction patterns of the cubic zinc selenide structural phase. The peaks observed in these films are in line with standard Powder Diffraction File (PDF) card number 00-037-1463 of The Joint Committee on Powder Diffraction Standard-International Centre for Diffraction Data (JCPDS-ICDD). 2 theta angles were observed for the films are shown in Table 2. Also, Peaks corresponding to tin (IV) oxide $\left(\mathrm{SnO}_{2}\right)$ with JCPDS-ICDD file number 00-046-1088 were observed at $33.781^{\circ}, 37.694^{\circ}$ and $50.689^{\circ}$ for film deposition under $1 \mathrm{~min}$., $37.848^{\circ}$, and $50.735^{\circ}$ for the film deposited under 3 mins and $38.041^{\circ}$ and $50.746^{\circ}$ for films deposited under 5 mins. The presence of tin (II) oxide is a result of the nature of the substrate (fluorine-doped tin oxide) used. The diffraction spectra showed an increase in intensity as deposition time increases and a slight peak shift towards higher angles was observed as shown in Table 2. Structural parameters such as crystallite size, dislocation density, and micro-strain were estimated using equations (2), (3), and (4) as presented by [24, 30-32]. The crystallite sizes (D) were evaluated using Debye-Scherrer's formula as shown in equation (2)

$$
D=\frac{0.9 \lambda}{\beta \cos \theta}
$$

Where $\beta$ is the full width at half maximum of the diffraction angles, $\lambda$ is the wavelength of Copper $k-\alpha 1$ radiation used for X-ray diffraction analysis and $\theta$ is the diffraction angle. The dislocation density $(\delta)$ of thin films was estimated using equation (3).

$$
\delta=\frac{1}{D^{2}}
$$




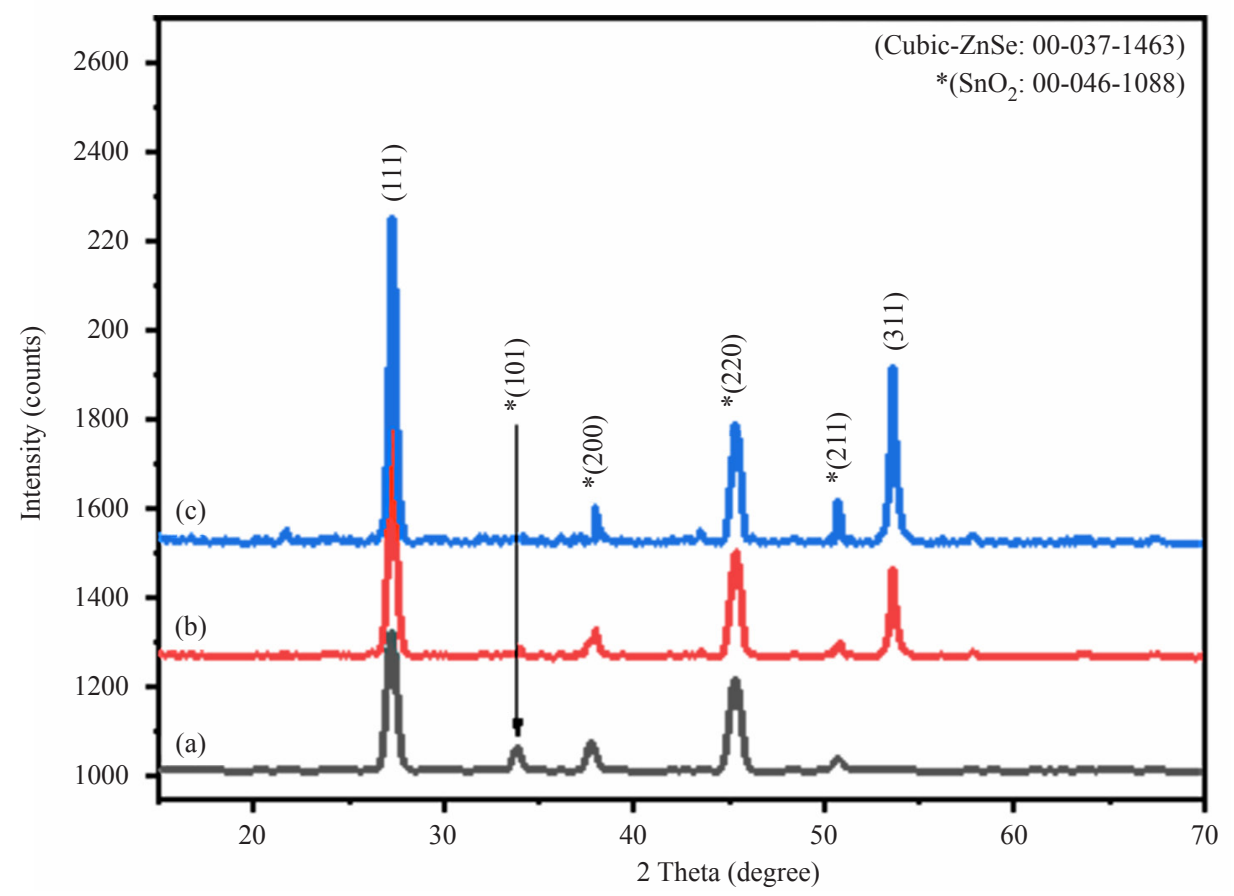
Figure 3. XRD pattern of cobalt doped zinc selenide thin films deposited by electrodeposition at varying deposition time (a) 1 min, (b) 3 mins, and (c)
5 mins

Table 2. Structural parameters of cobalt doped zinc selenide thin films at varying deposition time

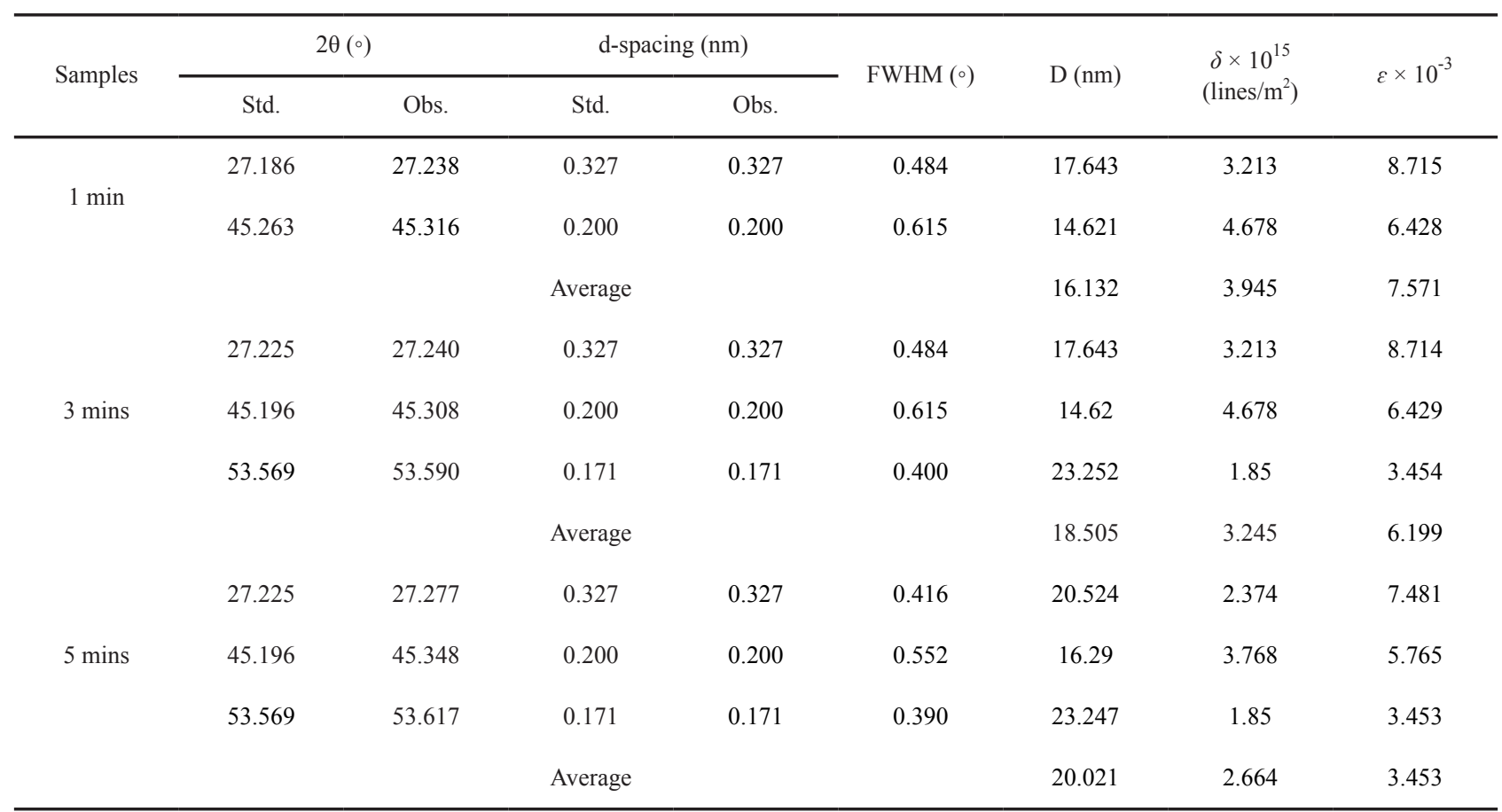

Micro-strain $(\varepsilon)$ of the thin film sample was estimated using the expression in equation (4). 


$$
\varepsilon=\frac{\beta}{4 \tan \theta}
$$

The average crystallite sizes of the films were found to be between $16.132 \mathrm{~nm}$ and $20.021 \mathrm{~nm}$. The Crystallite size of the films was found to increase as deposition time increased. Dislocation densities and micro-strains of the deposited thin films were found to decreases as deposition time increases. This result showed that an increase in deposition time caused enhancement of crystal structure in the cobalt doped zinc selenide thin films as confirmed by increased intensity and sharpness of the peaks observed for the film deposited under 5 mins. A similar cubic structural phase of zinc selenide has been obtained in the synthesis of zinc selenide thin films by $[15,19]$.

\subsection{Optical properties}

Transmittance $(T)$ of the film was evaluated using equation (5) as given by [33-34].

$$
T=10^{-A}
$$

Reflectance $(R)$ was obtained using the expression in equation (6) as given by [35-36].

$$
R=1-[T \times \exp (A)]^{\frac{1}{2}}
$$
$38]$.

The absorption coefficient $(\alpha)$ was calculated from the transmittance values using the equation (7) as given by [37-

$$
\alpha=\frac{1}{t} \ln \left(\frac{1}{T}\right)
$$

Where $t$ is film thickness obtained using equation (1). Extinction coefficient $(k)$ was obtained using equation (8) as given by [39-40].

$$
k=\frac{\alpha \lambda}{4 \pi}
$$

Refractive index $(\eta)$ of the films were calculated using equation (9) as given by [41-42].

$$
\eta=\frac{1+R}{1-R}+\sqrt{\frac{4 R}{(1-R)^{2}}-k^{2}} .
$$

The energy bandgap $\left(E_{g}\right)$ was estimated using Tauc's model of equation (10) as given by [45-46].

$$
(\alpha h v)^{n}=\beta\left(h v-E_{g}\right)
$$

Where $\beta$ is a constant, $n=2$ for direct band gap. The energy bandgaps of the films were obtained by extrapolating the straight portion of $(\alpha h v)^{2}$ the plot of against the photon energy $(h v)$ at $(\alpha h v)^{2}=0$. 


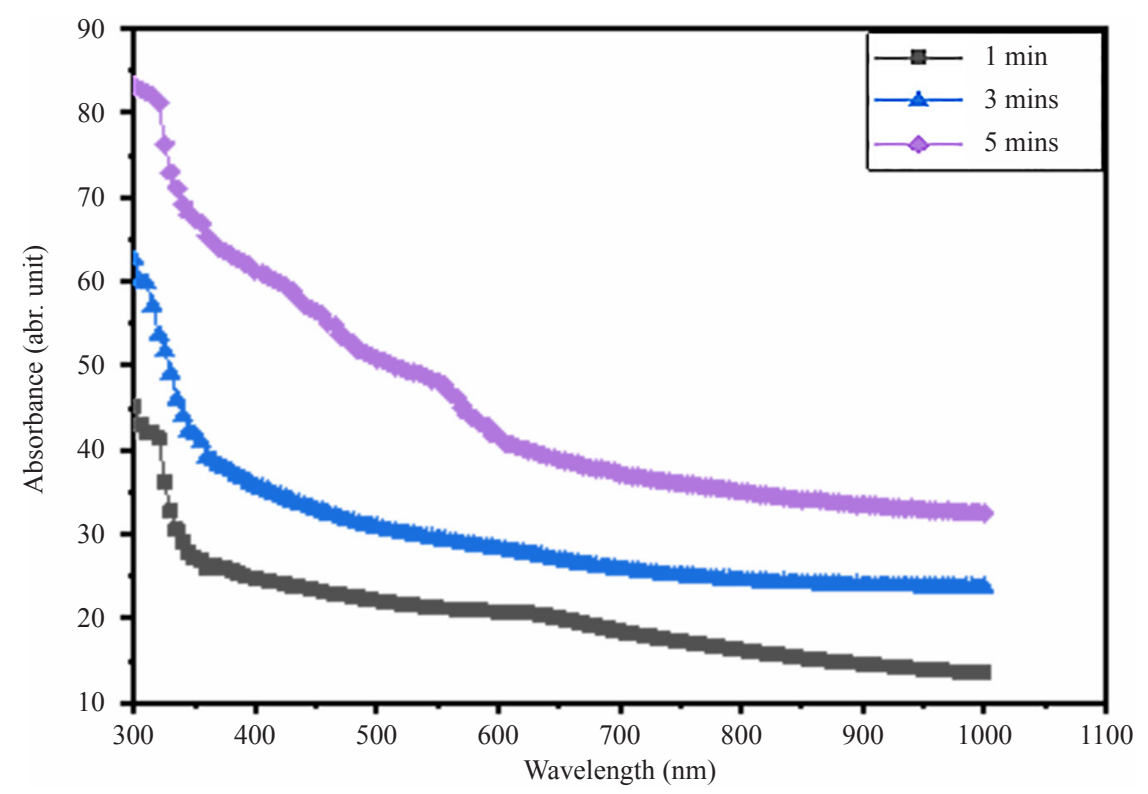

Figure 4. The Plot of absorbance against wavelength for cobalt doped zinc selenide thin films deposited at different deposition time

Figure 4 shows the graph of absorbance plotted against wavelength for cobalt doped zinc selenide thin films synthesized under different deposition times. The results showed that absorbance values decreased as the wavelength of photons increases. Also, absorbance values were found to increase as deposition time increases. This increase in absorbance values could be related to the increase in thickness of electrodeposited cobalt doped zinc selenide thin films as deposition time increases. Absorbance values of the deposited thin films ranged between $13.58 \%$. and $83.15 \%$. With this range of absorbance values, the deposited thin films of cobalt doped zinc selenide could be found applicable in the buffer layer of a thin-film solar cell and other optoelectronics device fabrications. Similar effects on the absorbance of thin film as deposition time increases have been obtained by [44, 47].

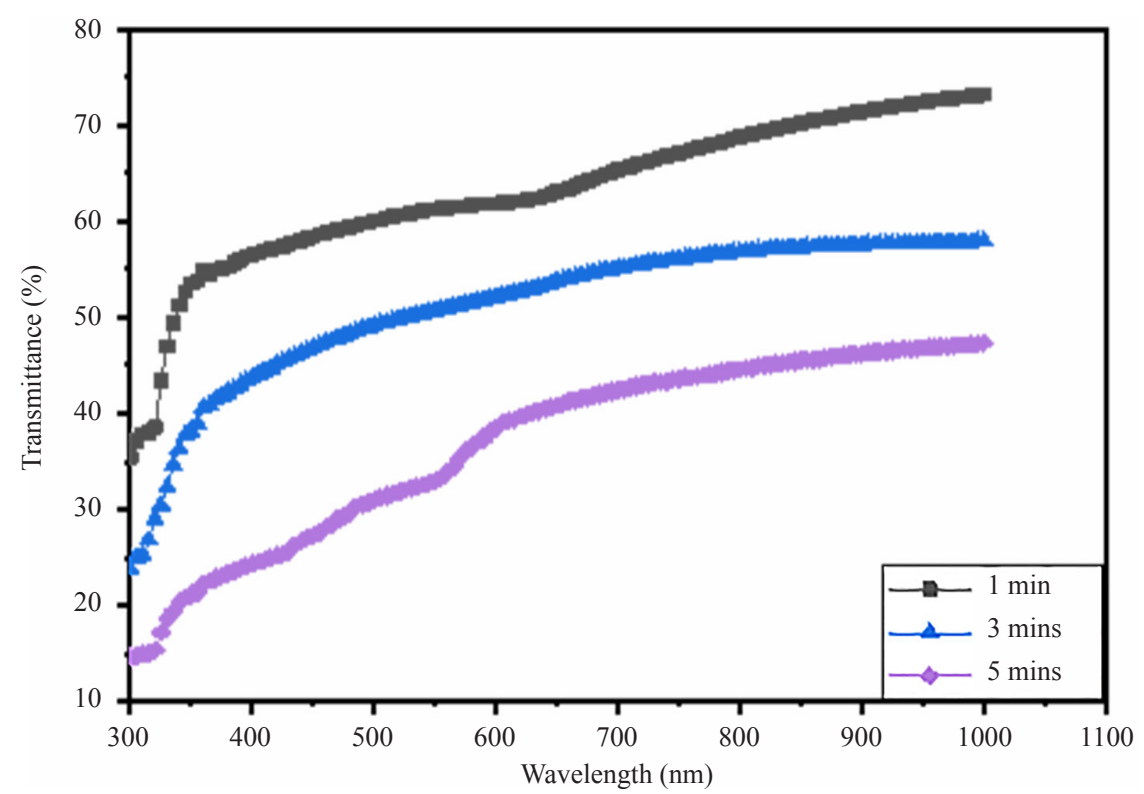

Figure 5. Plot of transmittance against wavelength for cobalt doped zinc selenide thin films deposited at different deposition time 
Figure 5 shows the graph of transmittance spectra plotted against wavelength for cobalt doped zinc selenide thin films synthesized under different deposition times. The results revealed that transmittance values increased as the wavelength of photons increases. Also, transmittance values were found to decrease as deposition time increases. This decrease in transmittance values could be due to an increase in thickness which does not allow many photons to be transmitted through the deposited thin film. Transmittance values of the deposited thin films fall between $24.40 \%$ and $73.15 \%$. Similar effects on the absorbance of thin film as deposition time increases have been obtained by [44, 48].

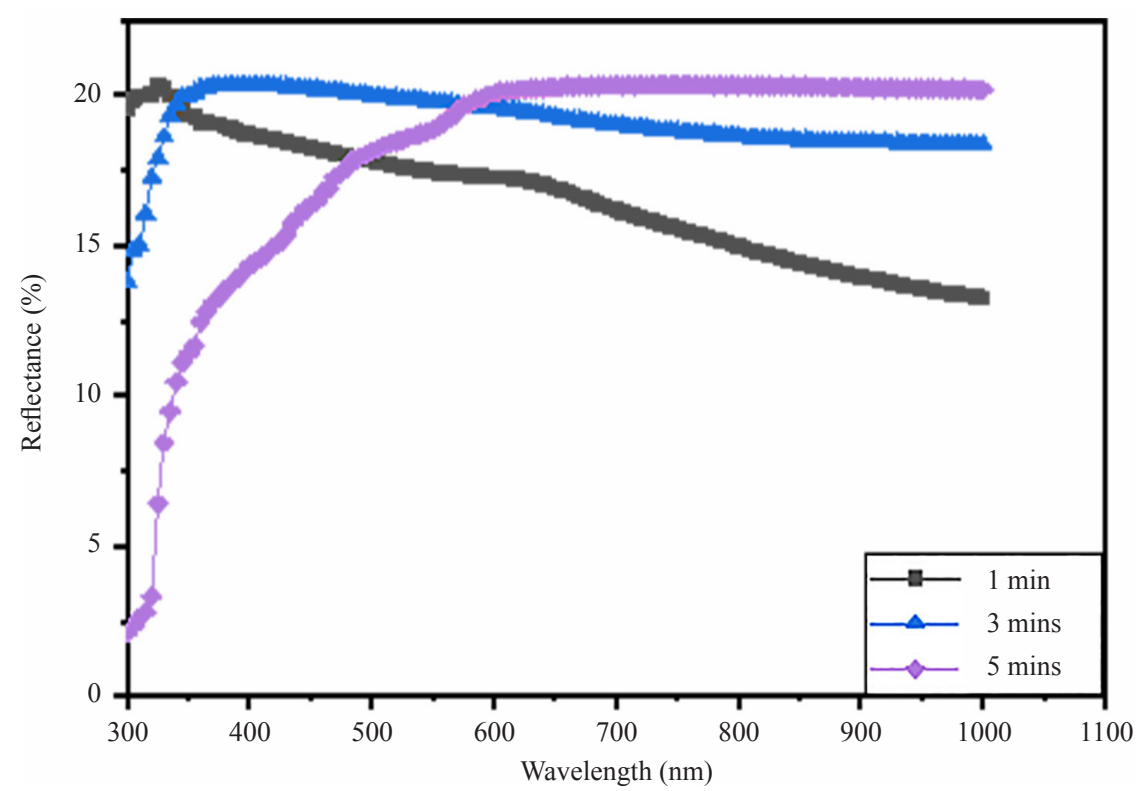

Figure 6. Plot of reflectance against wavelength for cobalt doped zinc selenide thin films deposited at different deposition time

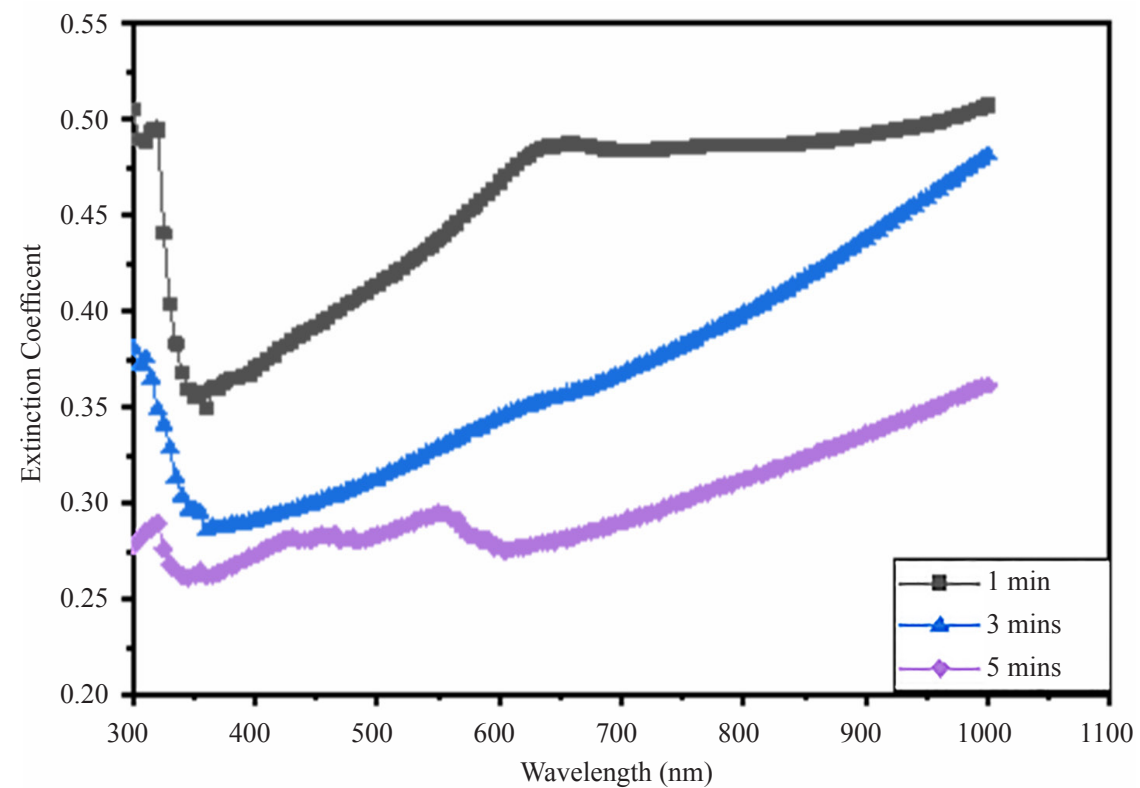

Figure 7. Plot of extinction coefficient against wavelength for cobalt doped zinc selenide thin films deposited at different deposition time 
Figure 6 shows the graph of reflectance against wavelength for cobalt doped zinc selenide thin films deposited at different values of deposition time. The reflectance values of deposited cobalt-doped zinc selenide were found to be low $(\leq 20.35 \%)$. The reflectance of the films showed a nonlinear relationship with deposition time. The range of values of reflectance obtained for the film is between $2.11 \%$ and $20.35 \%$. This range of reflectance values obtained from these deposited films showed that they could be used in anti-reflective coating and for shading off UV radiations.

Figure 7 shows the graph of extinction coefficient plotted against wavelength for cobalt doped zinc selenide thin films at varying deposition times. Extinction coefficient which is a measure of the amount of absorption loss when electromagnetic radiation propagates through the films was found to decrease from their values at $300 \mathrm{~nm}$ to lowest values of $0.35,0.29$, and 0.26 at $360 \mathrm{~nm}$ for cobalt doped zinc selenide thin films deposited at $1 \mathrm{~min}, 3 \mathrm{mins}$, and $5 \mathrm{mins}$ respectively. From these least points, the values increased as wavelength increases throughout the spectra. Extinction coefficient values of the deposited films were found to decrease as deposition time increased. Cobalt-doped zinc selenide thin films deposited under $1 \mathrm{~min}, 3 \mathrm{mins}$, and 5 mins have extinction coefficient values that ranged from 0.51-0.37, $0.48-0.29$, and $0.36-0.26$ respectively. These relatively moderate values of extinction coefficient made them potential materials for use as a buffer layer of thin-film solar cells and other optoelectronic device fabrications.

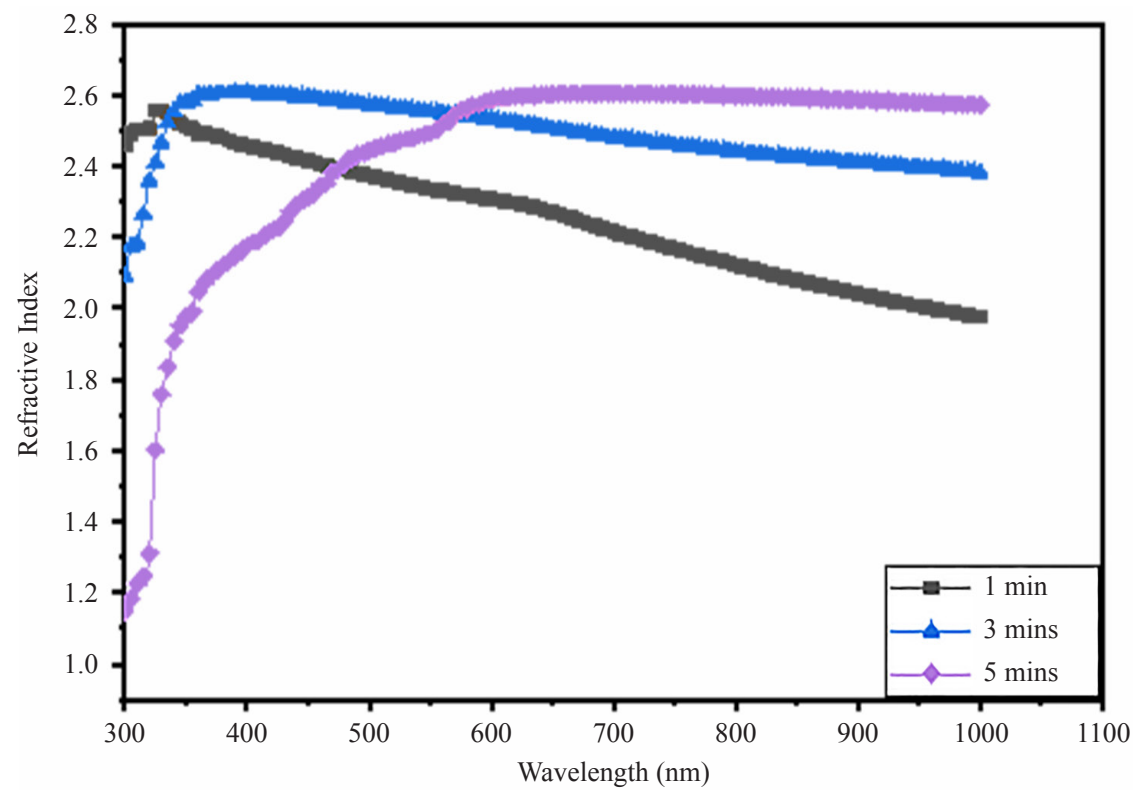

Figure 8. Plot of the refractive index against wavelength for cobalt doped zinc selenide thin films deposited at different deposition times

Figure 8 shows the graph of the refractive index against wavelength for cobalt doped zinc selenide thin films deposited at different values of deposition time. Refractive index values of deposited cobalt doped zinc selenide were found to be low $(\leq 2.46)$. Cobalt-doped zinc selenide thin film deposited under $1 \mathrm{~min}, 3 \mathrm{mins}$, and 5 mins have refractive index values that ranged from 2.46-1.98, 2.61-2.09, and 2.61-1.15 respectively. For film deposited at 5 minutes with the highest thickness of $399.62 \mathrm{~nm}$, the refractive index was found to be stable beyond the wavelength of $600 \mathrm{~nm}$. This stability in refractive index beyond $600 \mathrm{~nm}$ is similar to the result obtained by [49].

Figure 9 shows the Tauc plot of $(\alpha h v)^{2}$ against photon energy for cobalt-doped zinc selenide thin films deposited at different deposition times. From the plot, direct energy band gap values of the films were estimated by extrapolation of the straight portion of the graph along the photon energy axis where $(\alpha h v)^{2}=0$. Bandgap which is the gap in energy between the valence band and conduction band of the deposited film was found to be $2.85 \mathrm{eV}, 2.35 \mathrm{eV}$, and $2.10 \mathrm{eV}$ for the thin film deposited at $1 \mathrm{~min}, 3 \mathrm{mins}$, and $5 \mathrm{mins}$ respectively. The result showed a decrease in the energy band gap of films as deposition time increases. This confirmed the prospect offered in energy bandgap engineering of cobalt doped zinc selenide by altering deposition time. Similar effects on bandgap due to changes in deposition time using 

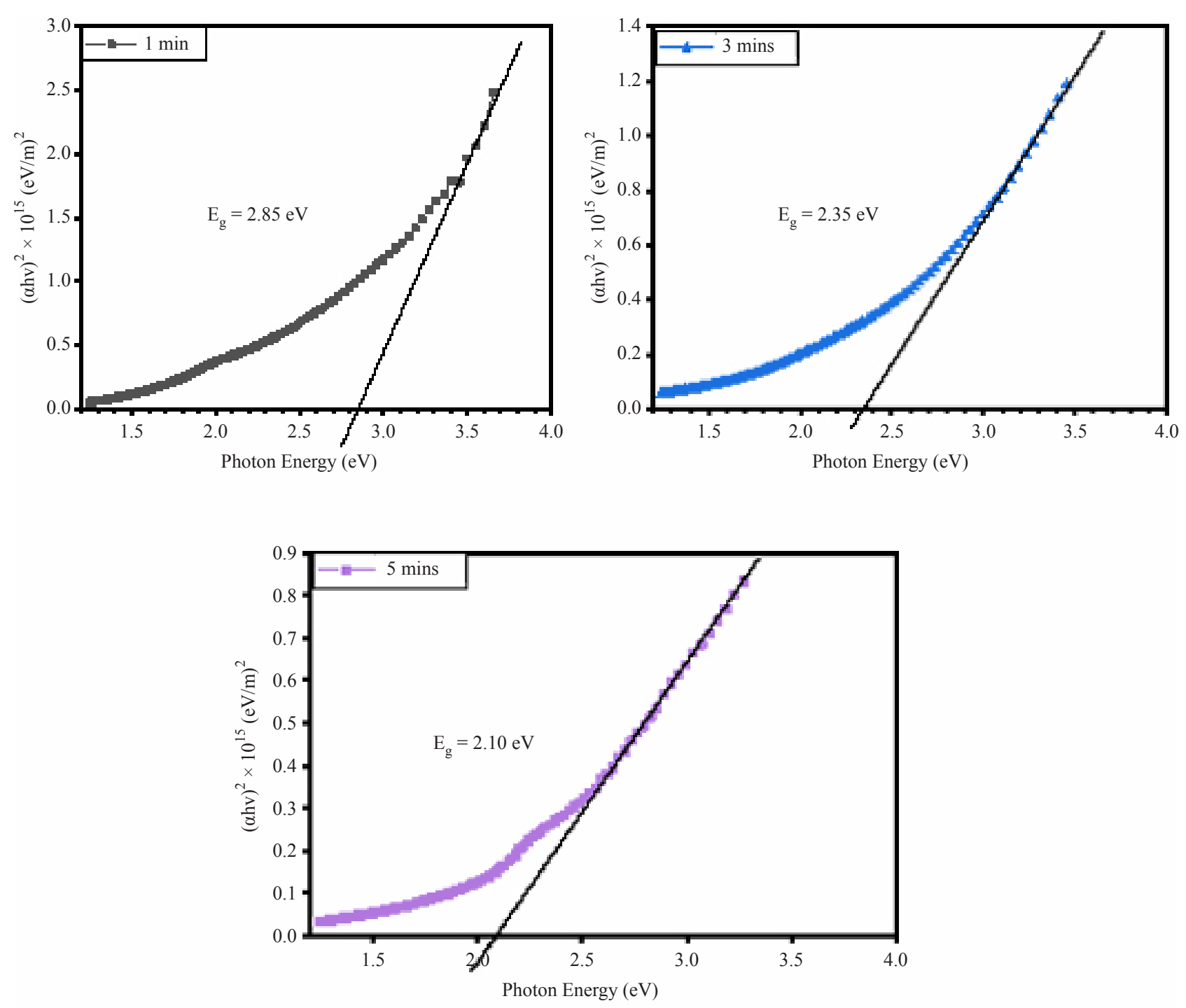

Figure 9. Plot of $(\alpha \mathrm{hv})^{2}$ against photon energy for cobalt doped zinc selenide thin films deposited at different deposition time

\subsection{Electrical properties}

The measurement of dc conductivities of the films was carried out using the four-point probe technique. Usually, in a four-point probe setup, a constant current passes through two outer probes, and an output voltage is measured across the two inner probes. Values of resistance (V/I) of the films could be estimated using measured current and voltage. Electrical conductivities and resistivity of the synthesized thin film were determined using expressions as given by [51$54]$ in equations (11) and (12) respectively.

$$
\rho=\frac{\pi t}{\ln 2}\left(\frac{V}{I}\right)=4.523 t\left(\frac{V}{I}\right)
$$

and electrical conductivity is given as 


$$
\sigma=\frac{1}{\rho}
$$

where $t$ is the estimated thickness of the films obtained by the gravimetric method. Electrical properties of cobalt doped zinc selenide thin films deposited at varying deposition times are shown in Table 3. The result showed that the variation in the deposition time has a resultant effect on the electrical properties of cobalt-doped zinc selenide thin films. An increase in deposition time caused a decrease in the electrical resistivity values of the deposited films. The resistivity values decreased from $15.90 \times 10^{4} \Omega \mathrm{cm}$ to $1.83 \times 10^{4} \Omega \mathrm{cm}$ while electrical conductivity values of the films were found to increase from to $6.30 \times 10^{-6} \mathrm{~S} / \mathrm{cm}$ to $5.47 \times 10^{-5} \mathrm{~S} / \mathrm{cm}$. Figure 10 showed the variation of electrical resistivity and conductivity with deposition time. The trend in resistivity and electrical conductivity obtained is in line with results obtained for semiconducting thin films by [55-57]. The reduction in the electrical resistivity or increase in the electrical conductivity is due to the improvement in the crystallinity of the deposited thin films which is a result of the increase in the film thickness [58-59].

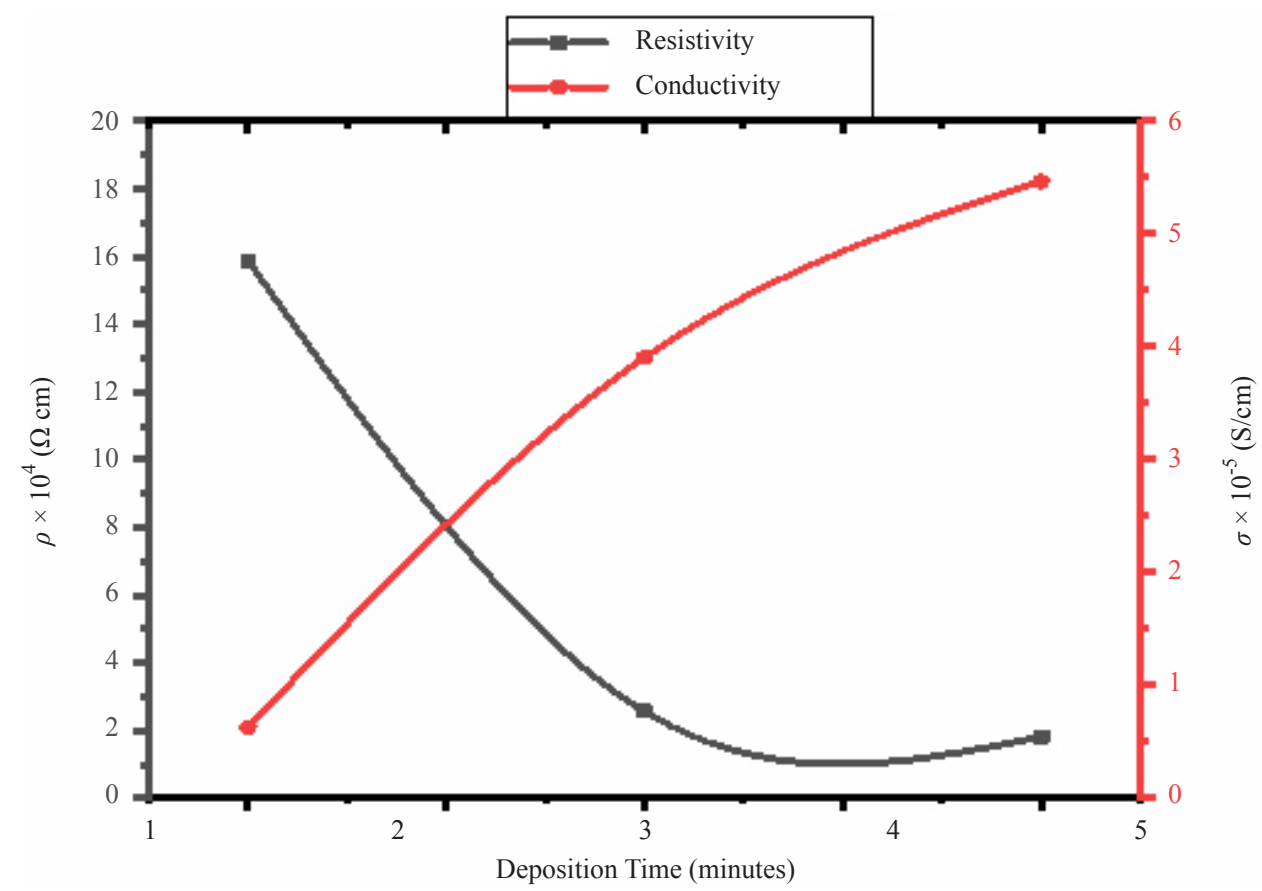

Figure 10. Variation of electrical resistivity and conductivity with deposition time

Table 3. Electrical properties of cobalt doped zinc selenide thin films deposited at different deposition times

\begin{tabular}{ccccccc}
\hline $\begin{array}{c}\text { Deposition } \\
\text { Time (mins) }\end{array}$ & $\begin{array}{c}V \times 10^{-3} \\
(\text { volts })\end{array}$ & $\begin{array}{c}I \times 10^{-10} \\
(\mathrm{amps})\end{array}$ & $\begin{array}{c}R \times 10^{7} \\
(\Omega)\end{array}$ & $\begin{array}{c}\text { Thickness } \\
(\mathrm{nm})\end{array}$ & $\begin{array}{c}R_{s} \times 10^{7} \\
(\Omega / \mathrm{sp})\end{array}$ & $\begin{array}{c}\rho \times 10^{7} \\
(\Omega \mathrm{cm})\end{array}$ \\
\hline 1.0 & 37.35 & 0.31 & 119.00 & 294.35 & 539.09 & $\begin{array}{c}\sigma_{e} \times 10^{-5} \\
(\mathrm{~S} / \mathrm{cm})\end{array}$ \\
3.0 & 21.01 & 1.17 & 17.89 & 315.94 & 81.02 & 3.93 \\
5.0 & 19.40 & 1.92 & 10.10 & 399.62 & 45.77 & 5.47 \\
\hline
\end{tabular}




\subsection{Morphological analysis}

Figure 11 shows SEM images of cobalt doped zinc selenide thin films deposited at varying deposition times of $1 \mathrm{~min}, 3 \mathrm{mins}$, and 5 mins respectively. SEM image of the film deposited under I min revealed agglomerated tiny nanofibres of different dimensions. SEM image of the film deposited at 3 mins showed that the surface of the thin film contained mostly spherical-like particles of different sizes. Larger particles of similar shapes are seen at the topmost layer of the surface. SEM image of the film deposited at 5 mins showed that the surface of the film is made up of interconnected nanofibres with spherical-like tiny particles encapsulated within the fabrics of the nanofibres.
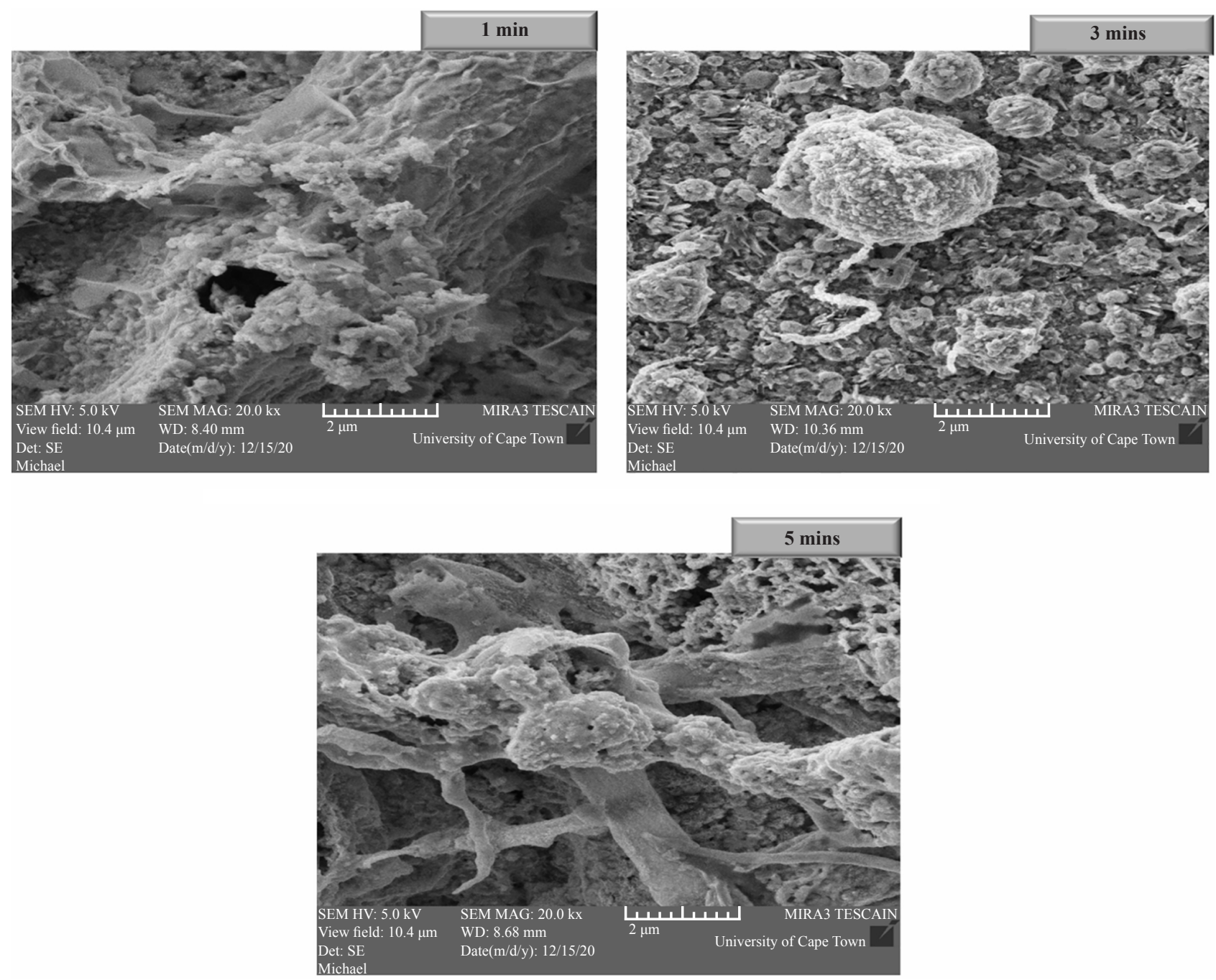

Figure 11. SEM images of cobalt doped zinc selenide at varying deposition time

\subsection{Compositional analysis}

EDS spectra of cobalt doped zinc selenide synthesized at different deposition times are presented in Figure 12. Atomic percentages of the elements in the deposited thin films were presented along with the EDS spectra. From these results, it was observed that deposition time favoured deposition of $\mathrm{ZnSe}$ thin films with a high percentage of selenium content. Also, zinc and cobalt contents were found to increase as deposition time increased from $1 \mathrm{~min}$ to 5 mins. Other elements such as oxygen $(\mathrm{O})$ and tin $(\mathrm{Sn})$ are a result of the substrate (FTO) used for the deposition. 

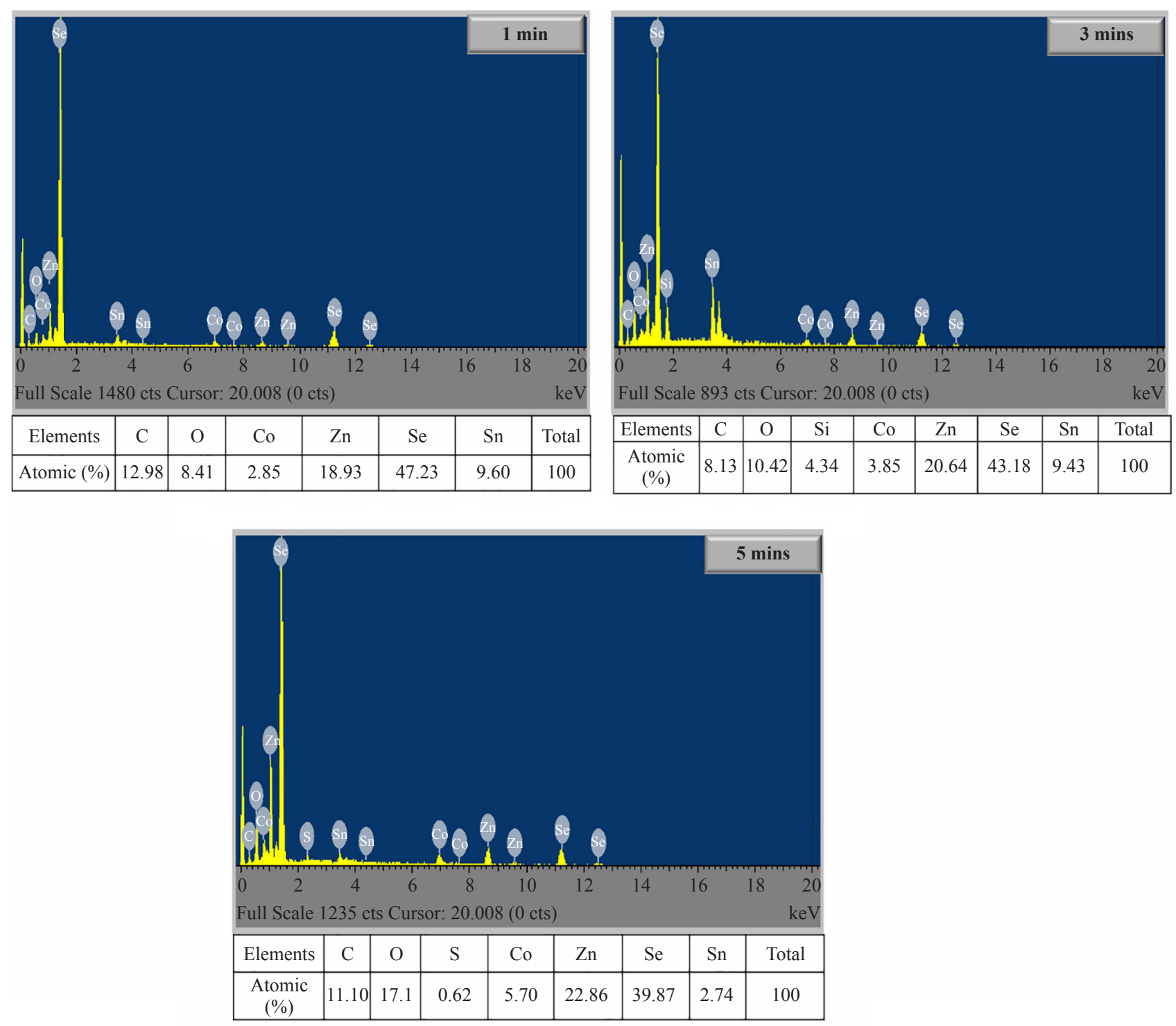

Figure 12. EDS spectra of cobalt doped zinc selenide at varying deposition time

\section{Conclusion}

Time optimized cobalt-doped zinc selenide thin films have been successfully electrodeposited unto conducting substrates (fluorine-doped tin oxide: FTO). Three films were deposited at different times of $1 \mathrm{~min}, 3$ mins, and 5 mins respectively. Thickness values of the formed films estimated using the gravimetric method ranged between $294.50 \mathrm{~nm}$ and $399.62 \mathrm{~nm}$. Electrodeposited cobalt doped zinc selenide showed good optical responses with absorbance that ranged from $13.58 \%$ to $83.15 \%$ while transmittance ranged from $24.40 \%$ to $73.15 \%$. The energy band gap of the films ranged between $2.10 \mathrm{eV}$ and $2.85 \mathrm{eV}$. Structural analysis revealed the formation of polycrystalline cubic phase of zinc selenide with crystallite size that ranged between $14.86 \mathrm{~nm}$ and $18.60 \mathrm{~nm}$. Other structural properties such as dislocation density and microstrain were found to vary with deposition time. Electrical resistivity values of $1.54 \times 10^{5} \Omega \mathrm{cm}-1.83 \times 10^{4} \Omega$ $\mathrm{cm}$ and electrical conductivity values of $6.30 \times 10^{-6} \mathrm{~S} / \mathrm{cm}-5.47 \times 10^{-5} \mathrm{~S} / \mathrm{cm}$. Based on the results, the film deposited at 5 minutes produced an optimal bandgap of $2.10 \mathrm{eV}$ and improved electrical conductivity of which make it most suitable for the absorber layer of solar cell and optoelectronic applications compared to others. These enhanced properties could be a result of an increase in cobalt ions as shown in the EDS results of figure 12. Micrographs of the films showed that 
the films were made up of nanoparticles of varying sizes and dimensions. EDS spectra confirmed the presence of zinc $(\mathrm{Zn})$, cobalt (Co), and selenium (Se) with traces of other elements. These properties positioned the deposited cobalt doped zinc selenide as potential materials for solar cell and optoelectronic device fabrication.

\section{Acknowledgement}

We wish to appreciate the contributions made by the staff of Nano Research Group of the University of Nigeria Nsukka, Enugu State, Nigeria, Electronic Microscopic unit, University of Cape Town, South Africa and National Geosciences Research Laboratories, Nigeria Geological Survey Agency, Kaduna State in the analysis of these samples.

\section{Funding information}

No funding was received for this research work.

\section{Conflict of interest}

There is no conflict of interest for this research work.

\section{References}

[1] Sayeed MA, Rouf HK, Hussain KMA. Effect of thickness on characteristics of ZnSe thin film synthesized by vacuum thermal evaporation. Journal of Theoretical and Applied Physics. 2020; 14: 251-259. Available from: https://doi.org/10.1007/s40094-020-00378-1.

[2] Hasaneen MF, Alrowaili ZA, Mohamed WS. Structure and optical properties of polycrystalline ZnSe thin films: validity of Swanepol's approach for calculating the optical parameters. Materials Research Express. 2020; 7(1): 1-15. Available from: https://doi.org/10.1088/2053-1591/ab6779.

[3] Zannier V, Cremel T, Artioli A, Ferrand D, Kheng K, Grillo V, et al. Optical properties of single wurtzite/zincblende ZnSe nanowires grown at low temperature. Journal of Applied Physics. 2015; 118(9): 1-6. Available from: https://doi.org/10.1063/1.4929821.

[4] Chen X-L, Huang B-J, Feng Y, Wang P-J, Zhang C-W, Li P. Electronic structures and optical properties of TM (Cr, Mn, Fe or Co) atom doped ZnSe nanosheets. RSC Advances. 2015; 5(128): 106227-106233. Available from: https://doi.org/10.1039/c5ra20223j.

[5] Temel S, Fatma Ö, Gökmen FO, Yaman E. An energy efficient way to produce zinc-based semiconductor thin films via chemical bath deposition technique. Journal of Sustainable Development of Energy, Water and Environment Systems. 2019; 7(2): 253-260. Available from: http://dx.doi.org/10.13044/j.sdewes.d6.0239.

[6] Tezel FM, Kariper IA. Effect of $\mathrm{pH}$ on the structural and optical properties of polycrystalline ZnSe thin films produced by CBD method. International Journal of Modern Physics B. 2019; 33(5): 1-13. Available from: https:// doi.org/10.1142/S0217979219500243.

[7] Hile DD, Swart HC, Motloung SV, Kroon RE, Egbo KO, Koao LF. The effect of annealing time on zinc selenide thin films deposited by photo-assisted chemical bath deposition. Journal of Physics and Chemistry of Solids. 2020; 140(109381): 1-11. Available from: https://doi.org/10.1016/j.jpcs.2020.109381.

[8] Buba ADA. Optoelectronic properties of zinc selenide (ZnSe) thin films deposited using chemical bath deposition (CBD) technique. British Journal of Applied Science and Technology. 2016; 14(3): 1-7. Available from: https://doi. org/10.9734/BJAST/2016/23622.

[9] Sagadevan S, Das I. Chemical bath deposition (CBD) of zinc selenide (ZnSe) thin films and characterization. Australian Journal of Mechanical Engineering. 2016; 15(3): 222-227. Available from: https://doi.org/10.1080/144 84846.2016.1264347.

[10] Rumberg A, Sommerhalter C, Toplak M, JaÈger-Waldau A, Lux-Steiner MC. ZnSe thin films grown by chemical vapour deposition for application as buffer layer in CIGSS solar cells. Thin Solid Films. 2000; 361-362: 172-176. 
Available from: https://doi.org/10.1016/S0040-6090(99)00790-7.

[11] Hsu CT, Su YK, Wu TS, Takahashi M, Nakada T, Hashimoto Y. Metalorganic chemical vapor deposition of ZnSe thin films on ITO/glass substrates. Applied Surface Science. 1993; 65-66: 831-834. Available from: https://doi. org/10.1016/0169-4332(93)90764-3.

[12] Yadav BK, Singh P, Pandey DK. Synthesis and non-destructive characterization of zinc selenide thin films. Zeitschrift für Naturforschung A: A Journal of Physical Sciences. 2019; 74(11): 1-7. Available from: https://doi. org/10.1515/zna-2019-0112.

[13] Chowdhury MT, Zubair MA, Takeda H, Hussain KMA, Islam MF. Optical and structural characterization of ZnSe thin film fabricated by thermal vapour deposition technique. Materials Science. 2017; 4(5): 1095-1121. Available from: https://doi.org/10.3934/matersci.2017.5.1095.

[14] Uğurlu HA, Hamurcu Y. Electrochemical growth of ZnSe thin films, characterization and heterojunction applications. Material Research Express. 2019; 6(116422): 1-9. Available from: https://doi.org/10.1088/2053-1591/ ab4679.

[15] Kim D, Park K, Jung H, Yoo B. Electrodeposition of chalcogenide ZnSe thin films with tailored compositions in alkaline aqueous citrate solutions. Journal of the Electrochemical Society. 2016; 163(7): D300-D304. Available from: https://doi.org/10.1149/2.0611607jes.

[16] Gromboni MF, Mascaro LH. Optical and structural study of electrodeposited zinc selenide thin films. Journal of Electroanalytical Chemistry. 2016; 780(1): 360-366. Available from: https://doi.org/10.1016/ j.jelechem.2016.04.037.

[17] Kumar S, Rajpal S. Synthesis and characterization of non-aqueous electrodeposited ZnSe thin film. World Academy of Science, Engineering and Technology, International Journal of Materials and Metallurgical Engineering. 2015; 9(3): 469-472. Available from: https://doi.org/10.5281/zenodo.1099932.

[18] Hassan SA, Bashir S, Zehra K, Ahmed QS. Structural, morphological and optical properties of pulsed laser deposited $\mathrm{ZnSe} / \mathrm{ZnSeO}_{3}$ thin films. Material Research Express. 2018; 5(046404): 1-13. Available from: https://doi. org/10.1088/2053-1591/aab4e1.

[19] Khan TM, Zakria M, Ahmad M, Shakoor RI. Optoelectronic study and annealing stability of room temperature pulsed laser ablated ZnSe polycrystalline thin films. Journal of Luminescence. 2014; 147: 97-106. http://dx.doi. org/10.1016/j.jlumin.2013.10.064.

[20] Li S, Wang L, Su X, Pan Y, Gao D, Han X. Optical properties of co-doped ZnSe thin films synthesized by pulsed laser deposition. Thin Solid Films. 2019; 692: 137599. Available from: https://doi.org/10.1016/j.tsf.2019.137599.

[21] Pawar ST, Chavan GT, Prakshale VM, Sikora A, Pawar SM, Kamble SS, et al. Solution grown ZnSe:Co nanocrystalline thin films: The characteristic properties. AIP Conference Proceedings. 2018; 1989(020036): 1-4. Available from: https://doi.org/10.1063/1.5047712.

[22] Mallikarjuna P, Sivasankar J, Begam MR, Rao NM., Kaleemulla S, Subrahmanyam J. Structural, optical and magnetic properties of Co doped ZnSe powders. Journal of Mechanics, Materials Science Engineering. 2017; 9(1): 195-200. Available from: https://hal.archives-ouvertes.fr/hal-01500600.

[23] Saha S, Johnson M, Altayaran F, Wang Y, Wang D, Zhang Q. Electrodeposition fabrication of chalcogenide thin films for photovoltaic applications. Electrochem. 2020; 1: 286-321. Available from: https://doi.org/10.3390/ electrochem 1030019.

[24] Egwunyenga NJ, Onuabuchi VC, Okoli NL, Nwankwo IE. Effect of SILAR cycles on the thickness, structural, optical properties of cobalt selenide thin films. International Research Journal of Multidisciplinary Technovation. 2021; 3(4): 1-9. Available from: https://doi.org/10.34256/irjmt2141.

[25] Awada C, Whyte GM, Offor PO, Whyte FU, Kanoun MB, Goumri-Said S, et al. Synthesis and studies of electrodeposited yttrium arsenic selenide nanofilms for opto-electonic applications. Nanomaterials. 2020; 10(8): 1-15. Available from: https://doi.org/10.3390/nano10081557.

[26] Barrios-Salgado E, Rodriguez-Lazcano Y, Pérez-Orozco JP, Colin J, Altuzar P, Campos J, et al. Effect of deposition time on the optoelectronics properties of $\mathrm{PbS}$ thin films obtained by microwave-assisted chemical bath deposition. Advances in Condensed Matter Physics. 2019; 2019(5960587): 1-8. Available from: https://doi. org/10.1155/2019/5960587.

[27] Abdallah B, Ismail A, Kashoua H, Zetoun W. Effects of deposition time on the morphology, structure, and optical properties of $\mathrm{PbS}$ thin films prepared by chemical bath deposition. Journal of Nanomaterials. 2018; 2018(1826959): 1-8. Available from: https://doi.org/10.1155/2018/1826959.

[28] Niknia F, Jamali-Sheini F, Yousefi R, Cheraghizade M. Effect of thickness on the optoelectronic properties of electrodeposited nanostructured SnS films. Optical and Quantum Electronics. 2018; 50(339): 1-14. Available from: https://doi.org/10.1007/s11082-018-1598-6. 
[29] Nweze CI, Ekpunobi AJ. Optical properties of electrodeposited zinc selenide films on conducting glass. Journal of Multidisciplinary Engineering Science and Technology. 2015; 2(6): 1449-1453.

[30] Khan TM. Into the nature of Pd-dopant induced local phonon modes and associated disorders in $\mathrm{ZnO}$; based on spatial correlation model. Materials Chemistry and Physics. 2015; 153: 248-255. Available from: http://doi. org/10.1016/j.matchemphys.2015.01.011.

[31] Offor PO, Ude SN, Whyte GM, Otung FU, Madiba IG, Bashir A, et al. Effect of concentration of trisodium citrate complexing agent on spray-synthesized $\mathrm{ZnS}$ thin films. Materials Today: Proceedings. 2021; 36(2): 133-140. Available from: https://doi.org/10.1016/j.matpr.2020.02.308.

[32] Ikhioya IL, Nkele AC, Ezeorba MC, Aisida SO, Maaza M, Ezema FI. Effects of erbium on the properties of electrochemically-deposited zirconium telluride thin films. Nanoarchitectonics. 2020; 2(1): 18-26. Available from: https://doi.org/10.37256/nat.212021503.

[33] Whyte GM, Awada C, Offor PO, Whyte FU, Kanoun MB, Goumri-Said S, et al. Experimental and theoretical studies of the solid-state performance of electrodeposited $\mathrm{Yb}_{2} \mathrm{O}_{3} / \mathrm{As}_{2} \mathrm{Se}_{3}$ nanocomposite films. Journal of Alloys and Compounds. 2021; 855: 157324. Available from: https://doi.org/10.1016/j.jallcom.2020.157324.

[34] Ezenwaka LN, Umeokwonna NS, Okoli NL. Optical, structural, morphological, and compositional properties of cobalt doped tin oxide (CTO) thin films deposited by modified chemical bath method in alkaline medium. Ceramics International. 2020; 46(5): 6318-6325. Available from: https://doi.org/10.1016/j.ceramint.2019.11.106.

[35] Augustine C, Nnabuchi MN, Chikwenze RA, Anyaegbunam FNC, Kalu PN, Robert BJ, et al. Comparative investigation of some selected properties of $\mathrm{Mn}_{3} \mathrm{O}_{4} / \mathrm{PbS}$ and $\mathrm{CuO} / \mathrm{PbS}$ composites thin films. Material Research Express. 2019; 6(066416): 1-10. Available from: https://doi.org/10.1088/2053-1591/ab1058.

[36] Guneri E. The role of Au doping on the structural and optical properties of $\mathrm{Cu}_{2} \mathrm{O}$ films. Journal of Nano Research. 2019; 58: 49-67. Available from: https://doi.org/10.4028/www.scientific.net/JNanoR.58.49.

[37] Egwunyenga NJ, Ezenwaka NL, Ezenwa IA, Okoli NL. Effect of annealing temperature on the optical properties of electrodeposited $\mathrm{ZnO} / \mathrm{MgO}$ superlattice. Materials Research Express. 2019; 6(10): 1-9. Available from: https:// doi.org/10.1088/2053-1591/ab42ab.

[38] Udachan SL, Ayachit NH, Udachan LA, Siddanna S, Kolkundi SS, Ramya S. Infrared optical constants of chromium nano-films. Journal of Physics: Conference Series. 2021; 1762(012026): 1-11. Available from: https:// doi.org/10.1088/1742-6596/1762/1/012026.

[39] Ongwen NO, Oduor AO, Ayieta EO. Effect of concentration of reactants on the optical properties of iron-doped cadmium stannate thin films deposited by spray pyrolysis. American Journal of Materials Science. 2019; 9(1): 1-7. Available from: https://doi.org/10.5923/j.materials.20190901.01.

[40] Aisida SO, Ahmad I, Zhao T, Maaza M, Ezema FI. Calcination effect on the photoluminescence, optical, structural, and magnetic properties of polyvinyl alcohol doped $\mathrm{ZnFe}_{2} \mathrm{O}_{4}$ nanoparticles. Journal of Macromolecular Science. 2020; 59(5): 1-14. Available from: https://doi.org/10.1080/00222348.2020.1713519.

[41] Gode F, Unlu S. Nickel doping effect on the structural and optical properties of indium sulfide thin films by SILAR. Open Chemistry. 2018; 16: 757-762. Available from: https://doi.org/10.1515/chem-2018-0089.

[42] Kariper IA. A new route to synthesis MnSe thin films by chemical bath method. Material Research. 2018; 21(2): 1-6. Available from: https://doi.org/10.1590/1980-5373-MR-2017-0215.

[43] Tyona MD, Akpen GE, Anejo I, Asemave K, Asogwa PU, Ezema FI. Aqueous chemical growth of ZnO/CdO nanocomposite thin films: effect of volume ratio and annealing on structural, morphological and optical properties. Journal of Materials Science: Materials in Electronics. 2020; 31: 21222-21232. Available from: https://doi. org/10.1007/s10854-020-04635-6.

[44] Ait HA, Atourki L, Labchir N, Ouafi M, Abouabassi K, Elfanaoui A, et al. Optical and dielectric properties of electrochemically deposited p- $\mathrm{Cu}_{2} \mathrm{O}$ films. Materials Research Express. 2020: 7(016424): 1-9. Available from: https://doi.org/10.1088/2053-1591/ab6772.

[45] Bunea R, Saikumar AK, Sundaram K. A comparison of optical properties of $\mathrm{CuO}$ and $\mathrm{Cu}_{2} \mathrm{O}$ thin films for solar cell applications. Materials Sciences and Applications. 2021; 12: 315-329. Available from: https://doi.org/10.4236/ msa.2021.127021.

[46] Tauc J, Grigorovici R, Vancu A. Optical properties and electronic structure of amorphous germanium. Basic Solid State Physics. 1966; 15(2): 627-637. Available from: https://doi.org/10.1002/pssb.19660150224.

[47] Meglali O, Attaf N, Bouraiou A, Aida MS, Lakehal S. One-step electrodeposition process of CuInSe 2 : Deposition time effect. Bulletin of Material Science. 2014; 37(6): 1535-1542. Available from: https://doi.org/10.1007/s12034014-0108-0.

[48] Okoli NL, Nkamuo CJ, Elekalachi CI. Effect of dip time on electrodeposited zinc oxide nanofilm. American Journal of Materials Synthesis and Processing. 2018; 3(2): 7-11. Available from: https://doi.org/10.11648/ 
j.ajmsp.20180302.11.

[49] Banerjee M, Jain A, Mukherjee GS. Microstructural and optical properties of polyvinyl alcohol/manganese chloride composite film. Polymer Composites: Structure, Morphology, and Surface Modification. 2019; 40(S1): E765-E775. Available from: https://doi.org/10.1002/pc.25017.

[50] Anand TJS, Rajan RKM, Warikh ARM, Abd RSI, Tee LK. Electrodeposited $\mathrm{NiX}_{2}(\mathrm{X}=\mathrm{S}$, Se) Thin films for solar cell applications. Aeronautics and Aerospace Open Access Journal. 2020; 4(1): 1-11. Available from: https://doi. org/10.15406/aaoaj.2020.04.00100.

[51] Li M-Y, Yang M, Vargas E, Neff K, Vanli A, Liang R. Analysis of variance on thickness and electrical conductivity measurements of carbon nanotube thin films. Measurement Science and Technology. 2016; 27(9): 1-12. Available from: https://doi.org/10.1088/0957-0233/27/9/095004.

[52] Waremra RS, Betaubun P. Analysis of electrical properties using the four-point probe method. E3S Web of Conferences. 2018; 73(13019): 1-4. Available from: https://doi.org/10.1051/e3sconf/20187313019.

[53] Askari MB, Shahryari M, Nanekarany S. Study and calculation electrical properties of silver thin layers by four-point probe method. Journal of Lasers, Optics and Photonics. 2017; 4: 150. Available from: https://doi. org/10.4172/2469-410X.1000150.

[54] Cemin F, Lundin D, Cammilleri D, Maroutian T, Lecoeur P, Minea T. Low electrical resistivity in thin and ultrathin copper layers grown by high power impulse magnetron sputtering. Journal of Vacuum Science and Technology A: Vacuum, Surfaces, and Films. 2016; 34(5): 1-7. Available from: https://doi.org/10.1116/1.4959555.

[55] Rahman KS, Harif MN, Rosly HN, Kamaruzzuman MIB, Akhtaruzzaman M, Alghoul M, et al. Influence of deposition time in CdTe thin film properties grown by Close-Spaced Sublimation (CSS) for photovoltaic application. Results in Physics. 2019; 14(102371): 1-9. Available from: https://doi.org/10.1016/j.rinp.2019.102371.

[56] Kamli K, Hadef Z, Chouial B, Hadjoudja B. Thickness effect on electrical properties of copper oxide thin films. Surface Engineering. 2019; 35(1): 86-90. Available from: https://doi.org/10.1080/02670844.2018.1475052.

[57] Erken O, Gunes M, Ozaslan D, Gumus C. Effect of the deposition time on optical and electrical properties of semiconductor $\mathrm{ZnS}$ thin films prepared by chemical bath deposition. Indian Journal of Pure and Applied Physics. 2017; 55(7): 471-477.

[58] Choudhary R, Chanhan RP. Thickness dependent variation in structural, optical and electrical properties of CdSe thin silms. Journal of Material Science: Material in Electronics. 2019; 30: 5753-5759. Available from: https://doi. org/10.1007/s10854-019-00870-8.

[59] Vishwakarma R. Thickness dependent structural, electrical and optical properties of ZnS thin films deposited by thermal evaporation. Ukraine Journal of Physics. 2017; 62(5): 422-431. Available from: https://doi.org/10.15407/ ujpe62.05.0422. 